ISSN: 2162-3104 Print/ ISSN: 2166-3750 Online

Volume 8, Issue 4 (2018), pp. 1865-1878

(C) Journal of International Students

http://jistudents.org/

doi: $10.5281 /$ zenodo. 1468100

\title{
Developing Culturally Responsive Programs to Promote International Student Adjustment: A Participatory Approach
}

\author{
Laura R. Johnson \\ University of Mississippi, USA \\ Tanja Seifen-Adkins \\ University of Mississippi, USA \\ Daya Singh Sandhu \\ Lindsey Wilson College, USA \\ Nadezda Arbles \\ University of Mississippi, USA \\ Hitomi Makino \\ University of Mississippi, USA
}

\begin{abstract}
International students in the United States face acculturative stress, yet few seek counseling. In this paper, we highlight a participatory approach to develop culturally and contextually competent programs to enhance international student adjustment and engagement. We combined findings from the Acculturative Stress Scale of International Students (ASSIS) with interviews eliciting international student concerns and ideas for programming. On the ASSIS, randomly selected international students $(n=40)$ expressed high levels of acculturative stress. These students, along with key informants $(n=5)$ and international student leaders $(n=8)$ formed focus groups, and provided suggestions for programs. Based on these formative results, we developed and described a variety of programs. Our experiences with participatory approaches suggest a promising avenue for enhancing cultural and contextual competence in international student programming.
\end{abstract}

Keywords: international students, adjustment, participatory approach, program development

International students often experience acculturative stress which negatively impacts their experience in the United States (e.g. Smith \& Khawajar, 2011). Researchers and practitioners argue that the psychosocial adjustment of international students may be enhanced with a continuous and multi-pronged approach that includes traditional counseling in addition to a range of other, more specialized, groups and outreach services (e.g. Engel, Insalaco, 
Singaravelu, \& Kennon, 2007; Johnson \& Sandhu, 2007; Jackson, Ray, \& Bybell, 2013; Smiljanic, 2017). This study grew out of an effort to develop programs to meet the psychosocial and cultural adjustment concerns of intentional students at a college town in the Southern US.

The initial goal of the project was to assess acculturation concerns of international students and gather information to aid our program development efforts. We used the guiding principles of Participatory Action Research (PAR; Reason \& Bradbury, 2001) to enhance the cultural and contextual relevance of programming efforts. Perspectives of various stakeholders and international students were considered throughout the different phases of the project (Reason $\&$ Bradbury, 2001). International students have been involved as research participants, program developers and facilitators, and project coordinators. In this paper, we describe the Cultural Connections Project (CCP), including our initial assessment of international student acculturation concerns, program development, implementation, initial feedback and modification, and plans for ongoing development and evaluation.

\section{Acculturative Stress in International Students}

In addition to the common concerns of US college students, international students face unique stressors related to acculturation, the process of changing one's values, behaviors, and beliefs while learning to navigate a new cultural environment and engaging in cross-cultural exchange (Berry, 1997, 2008). More specifically, international students have to adjust to language barriers, different academic systems, cultural conflicts, racial discrimination, social isolation and emotional concerns (Smith \& Khawajar, 2011). While they may be among the most talented and well-resourced in their home countries, international students face challenges of daily living in a foreign environment, usually without adequate information or preparation (Jacob, 2001). These common challenges can result in acculturative stress, even among the most robust. Acculturative stress is an umbrella terms, used to describe stress associated with acculturation. Symptoms that may range from mild to severe distress and include homesickness, anxiety, loneliness, depression, and identity or values confusion. Irritability, anger, substance abuse, and family conflict may also result (Berry, Kim, Minde, \& Mok, 1987; Gebhard, 2012; Hirai, Frazier, \& Syed, 2015).

Although a certain amount of acculturative stress is expected when adjusting to a new cultural environment, symptoms can negatively impact international students' experiences and interfere with performance. Students may experience a range of problems, such as loneliness, homesickness and irritability, depression, confusion, and disorientation (Hayes \& Lin, 1994; Sandhu, 1994; Smith \& Khawajar, 2011; Smiljanic, 2017; Tsai, Wang, \& Wei, 2017). It is common to find international students suffering from persistent lack or loss of appetite and sleep, low stamina and energy levels, and other stress-related physical complaints (Mori, 2000). Communication difficulties, exposure to unfamiliar environments and cultures, academic demands and social isolation can become psychological stressors (Gebhard, 2012).

Programs to support international students, such as individual and group counseling could ameliorate stress associated with cultural adjustment (Engel et al., 2007). However, many international students do not seek out psychological help or may be unfamiliar with counseling services (Komiya \& Eells, 2001; Hwang, Bennett, \& Beauchemin, 2014; Lee, Ditchman, Fong, Piper, \& Feigon, 2014). Seeking help from counseling or mental health centers is stigmatized in some students' home cultures, while others may view counseling services as disjointed, culturally unpalatable, insensitive to their unique concerns, or simply not applicable to their problems (Johnson \& Sandhu, 2007). 
Given that many will not seek formal mental health services, alternative programs are needed to reach these students. A culturally competent program should address students' expressed concerns, be culturally appropriate in content and processes, and minimize potential stigmas associated with help-seeking or adjustment problems (Johnson \& Sandhu, 2007). In developing effective programs, particular attention must also be given to more localized, contextual factors that may impact student adjustment and needs. It is important that program targets (i.e., international students) have a voice in the types of programs that will be useful and desirable. One approach with the potential to enhance the cultural appropriateness, utility, and sustainability of programs is centered on the idea of stakeholder empowerment through active participation in research and programming, participatory action research (Reason \& Bradbury, 2001).

\section{Participatory Action Research}

Participatory action research (PAR) evolved from social and educational research that strived to create positive changes in communities or societies (e.g., Lewin, 1946; Reason \& Bradbury, 2001). PAR is an orientation rather than a specific method. Lewin (1946) described action research as a cyclical process involving problem identification, observation, action planning, and action steps, often in the form of intervention (e.g. Kemmis, McTaggert, \& Nixon, 2013). Action steps become the focus of observation and problem identification such that new information is constantly being incorporated into intervention and research. A feedback loop is created and the process is ongoing. Another central feature of PAR is the identification and inclusion of stakeholders as active participants engaged in the entire process, from problem identification to research, action planning, evaluation, and so on. This aspect of PAR can result in enhanced "buy in" from program stakeholders and an increased valuing of programs due to a better fit with needs.

\section{Present Study}

Our main aim with this study was to determine how to best ease acculturative stress among international students in our university context. Previous efforts to offer education or services had failed, with stakeholder explanations that ranged from a lack of perceived relevance to poor timing, and/or an explicit and thus stigmatizing mental health approach. To increase contextual and cultural appropriateness of interventions for international students, a group of US and international faculty and students held approximately five meetings to discuss ways to fill gaps in existing services. After some reflection, the team decided that there was a need to reach out to students themselves, seek more information and get their ideas. The principles of PAR were used to guide the approach. Perspectives of different program stakeholders were included, and international students had a voice throughout the different phases of the project, not only as research participants, but as members of the research team, program developers, facilitators and coordinators.

\section{METHOD}

\section{Participants}

Participants were foreign nationals on an international student visa enrolled at a mid-size University in a college town in the Southern US. Participants included 40 international students, eight international student leaders representing campus groups, such as the Intentional 
Student Organization and the Malaysian Student Association, and five key informants who worked with international students on campus. The average age of participants was 28 $(S D=7.16)$. Students represented 13 different countries, with a majority from Asian countries (71\%), followed by African countries (20\%), European countries (6\%), and Central and South American countries (2\%). Among total 48 students, $56 \%$ were women and $64 \%$ were single. Twenty-two percent had a spouse residing with them, and $9 \%$ had children. Participants were equally enrolled, in bachelor, masters or doctoral degree programs. The length of stay in the US ranged from 4 months to 9 years $(M=2.5$ years, $S D=2$ years $)$. Key informants worked closely with international students (e.g., Office of International Programs, advisors, ESL teachers).

\section{Recruitment}

Participants were recruited using a combination of email letters of invitation (to the selected names) and in-person invitations for key informant interviews. Access to international student information was obtained through the university's International student office database. Participants were invited to attend a meeting to express their concerns and provide opinions about solutions. Several meeting dates were provided. Follow up e-mails were sent one time. The first invitations resulted in 5 students with schedule conflicts and 4 that did not respond. We did another random selection of $10 \%$ and sent a second round of invites which completed the random student sample. International student leaders of organizations (e.g., Indian Student Association, Afro-Caribbean Student Association, Chinese Student Association, International Student Association) were invited to a separate key informant meeting, whereas individual meetings were requested with other stakeholders (advisors).

\section{Instruments}

Students completed questionnaires to assess socio-demographics and acculturative stress. The Acculturative Stress Scale for International Students (ASSIS) (Sandhu \& Asrabadi, 1994) was used to measure adjustment problems. The ASSIS is a Likert-type scale with 36 items rated from 1 (strongly disagree) to 5 (strongly agree) across 7 subscales: discrimination, homesickness, perceived hate, fear, stress due to change, guilt and miscellaneous. Several studies reported adequate psychometric properties for this measure of acculturative stress in international students, with an internal consistency coefficient of .92 or above (Constantine, Okazaki, \& Utsey, 2004; Yeh \& Inose 2003).

Semi-structured, open-ended interviews were conducted, beginning with the question "What are one or two major adjustment concerns you face as international students at this university?" Open-ended questions were followed by discussions. Next, students were asked about areas not spontaneously reported (e.g. tell us about any experiences with racism or discrimination you have faced). Areas were developed in advance based on the literature (Johnson \& Sandhu, 2007; Mori, 2000; Sandhu \& Asrabadi, 1994), and included: language and communication, social and cultural differences, relationships, perceived discrimination, and psychological adjustment and coping. The second part of the focus group was designed to elicit ideas about how to develop services to ease adjustment concerns. This began with "What are your ideas about how to address these concerns? What suggestions do you have?" Student leaders and key informants were asked similar open-ended questions about areas of adjustment difficulty and programs. They also ranked the relative importance of different areas of concern. 


\section{Data Collection and Analysis}

Upon the agreed time and place, data were collected with small groups of international students. Nine focus group meetings were held with students, including one with student leaders of international organizations. Students first completed the ASSIS, followed by the interview and discussion. Focus group interviews were facilitated by two members of the research team and detailed notes were recorded by one or two members acting as observers. Key informants were interviewed individually by the first author. Descriptive statistics were derived from the socio-demographic questionnaire and the ASSIS. After each focus group, facilitators and observers recorded comments about the content and process of the interview. During weekly post-interview meetings, perspectives were shared and the entire team reviewed the notes to identify content themes and categories. While some themes were based on the literature (e.g. communication, social), other concerns arose from the data (Miles \& Huberman, 1994) and were related to the local context, such as problems of no public transportation and a lack of recreational activities.

\section{RESULTS}

Table 1 summarizes the descriptive statistics for the total score and subscales of the ASSIS. While our mean of total ASSIS scores of 93.65 (19.36) appears higher than the psychometric study, our sample mean falls just within two standard deviations (42.32) from their mean of 66.32 , indicating it remains within "normal range" according to the measure developers (Sandhu \& Asrabadi,1994). Looking at subscales on the ASSIS, 'homesickness' was ranked highly across participants; the second highest rating was 'stress due to change' and 'miscellaneous.' Overall, 'feeling guilty' was lowest. Other results on the ASSIS are discussed, where relevant alongside qualitative data from interviews.

Table 1. Summary of acculturative stress scores for international students $(n=40)$.

\begin{tabular}{lc}
\hline Area of concern & $\boldsymbol{M}(\boldsymbol{S D})$ \\
\hline Homesickness & $3.16(.89)$ \\
Stress due to change & $2.79(.75)$ \\
Miscellaneous & $2.78(.61)$ \\
Perceived discrimination & $2.69(.78)$ \\
Perceived hate & $2.27(.72)$ \\
Fear & $2.08(.67)$ \\
Guilt & $2.05(.21)$ \\
ASSIS Mean & $2.6(.54)$ \\
ASSIS Total Score* & $93.65(19.36)$ \\
\hline
\end{tabular}

Note. Total scores on the ASSIS range from 36 to 180 . What was the scale 1 to 5 ?

During focus groups and key informant interviews, participants shared adjustment concerns in communication, academics, cultural differences, social concerns, discrimination, and socialemotional functioning, and practical concerns related to daily living. Below we summarize students' concerns in each major domain and provide the strategies and suggestions provided by our participants. 


\section{Language and Communication Difficulties}

It is often noted that language barriers are the most significant and prevalent problem for international students (e.g. Mori, 2000; Gebhard, 2012). The central and pervasive influence of communication on students' personal, social and academic adjustment was supported in our interviews. Although varied in language abilities, communication was among the first problems mentioned and was reported by nearly all participants. Key informants also rated communication and language problems as the greatest area of adjustment concerns (see Table 2). Students reported accompanying psychological distress. For example, a participant from China sadly recalled, "I felt blind, deaf, and dumb. I did not know what was going on, and how things worked...it takes long time to even ask questions." Particular to the setting of this study, many students were unfamiliar with the Southern dialect and had difficulty getting used to the accent and idioms.

Many international students are not familiar with the US educational system and pedagogical style. In classes where verbal participation comprises a significant portion of the grade, students felt added academic stress and pressure. Participants pointed out that difficulty speaking out in class is coupled with cultural differences that value listening rather than talking, which is contrary to American classroom expectations and ideals. Asking questions of professors is considered disrespectful in some cultures and many students reported that participation in class discussion is a major struggle even after two or more years in the US.

Students shared their successful experiences of improving their own English skills through interactions with US students. Some students spoke positively about existing opportunities for English improvement including having American roommates, church Bible study partners, and English classes offered on campus. It was suggested that more programs be available to help with oral presentations and communication skills. Additionally, students felt that more sensitivity and awareness was needed on the part of faculty and staff to help them adjust to different academic expectations.

\section{Social and Cultural Issues}

Consistent with the literature, our participants reported concerns associated with the loss of familial, social and cultural supports (e.g. Williams \& Johnson, 2011; Bai, 2016). Many participants reported difficulty making US friends and thus, sought security with other international friends. Several participants mentioned the frustration of having only co-national friends. For those with US friends, participants expressed dissatisfaction with the quality of the US student relationships, suggesting that they were lacking in depth and commitment. Some attributed difficulties to a lack of common interests between themselves and US students. Students expressed disappointment at US students' lack of interest and knowledge about global issues and other cultures.

Several students reported facing cultural conflicts related to religion at this university, which is in the bible belt of the US. Some felt religion was forced on them, others were taken aback by the open discussion of what they considered a personal matter. Sometimes, religious conflicts hindered international students' attempts to make friends. For example, one participant reported that she was assigned to several peer partners but they all discontinued calling her after she refused to go to church with them. Another stated that she was offended when student explicitly asked questions about their religion, such as 'Are you Christian?'. Other students reported feeling dissatisfied with the structure of the university's community, feeling shut out from some services and organizations, such as the campus Greek system which 
tends to dominate and membership in such an organizations was associated with less positive attitudes toward international students (Williams \& Johnson, 2011).

Students suggested a need for different casual activities that involve international students and US students, such as game nights, potluck affairs, and cultural celebrations. One student felt that the "international groups should be more visible during the orientation week." A common concern was a lack of information about what to do with their spare time in this small, rural town. Participants also pointed to the need for reaching out to international families, such as spouses. They suggested having activities and interest meetings in which international students can easily participate, such as interest-focused clubs, like sports or cooking that involve fun activities. International students wanted US students to be involved in these activities, as they reported that having common interests helps them build friendships.

\section{Emotional, Psychological and Stress-Related Concerns}

Homesickness was the most common psychological concern in the focus groups, congruent to reports on the ASSIS. Loneliness was also a serious concern for international students and their spouses and families, especially those who do not enroll in school. Some students expressed psychological stress such as feeling inferior, feeling unwelcomed and feeling as though others looked down on them. Key informants and student leaders noted severe depression among some students. Quantitative data confirms this report with "Culture shock/ Stress due to change" being the second highest score among means of ASSIS subscales, and total ASSIS scores nearly being outside of the 'normal' range.

Several students felt a class on US culture should be offered, as it would aid in their knowledge of the cultural expectations and norms of US society, and make the transition smoother. Students felt that it would be helpful for the International Office to "check-in" with international students after they have been in the country for a few months.

While international students may be reluctant to actively seek help, or share their personal issues and emotions with others (Lee, 2014; Hwang, Bennett, \& Beauchemin, 2014), those participating in this study stated that it was good to share their experiences in the focus groups. Participants wanted to have more opportunities to share their adjustment problems with other international students who have faced similar problems. For them, the focus group seemed to serve as a proactive method of counseling or outreach, which has been suggested in lieu of traditional counseling or reactive counseling (Sandhu, 1994; Smiljanic, 2017). The group structure seemed to be safe and culturally appropriate for international students (Walker \& Conyne, 2007).

\section{Daily Living and Practical Matters}

Challenges related to practical living in a Southern rural town were among the first stressors mentioned by students after language. Fulfilling basic and immediate needs, such as housing, registering for classes, and handling visa-related problems are difficult, especially when unfamiliar with the systems and rules. Challenges were exacerbated by language and communication. A majority of students were shocked to learn that there was no public transportation in the small town. Most viewed this as a serious challenge to their initial and long-term adjustment.

One suggestion was to set up a mentoring system in which an incoming international student is matched with another international student who has been living in the U.S. for some time (Engel et al., 2007). International students could receive valuable advice and support from 
students who have already dealt with a lot of these concerns and can truly understand the frustrations they may experience in the process.

\section{Racism and Discrimination}

Scores on the ASSIS scale for perceived discrimination were lower than reported norms. Likewise, complaints about discrimination seldom arose spontaneously during the interviews and were rated lowest among key informants (see Table 2). However, as discussions about social interactions preceded, issues of prejudice, discrimination, and overt racism emerged. Participants reported overt and subtle discrimination in academic, social, and community settings. In the classroom, international students disliked forming groups or pairs with other students because their attempts to join were often rejected by US students. One participant shared that outside of the class, her classmates pretended not to know her. Some African students said that White Americans gave them the message that, as "Blacks", it was expected and assumed that they would hang out primarily with African Americans. More direct and more serious racist threats and attacks were reported, such as a Malaysian student who had beer cans thrown at him with US students yelling, "go back to China" while he was playing tennis. In the campus dorm, several US students shouted "go back home, foreigners!" to one international student, who eventually moved for fear of her safety.

International students did not make explicit suggestions about reducing racist incidents. At the same time, students expressed that the racism was largely due to ignorance, and that if students were educated more, they would not be so ethnocentric in their thinking. Encouraging US students to learn about other countries and cultures was encouraged, such as giving students assignments to participate in international events. The need for cultural diversity training among international students was also noted. Information gathered suggested that a number of international students have been influenced by negative stereotypes of US American ethnic minority groups. For example, students from Asian countries reported fear and apprehension around African American males.

\section{Key Informant Perspectives}

Key informants stated concerns that echoed those of students. They ranked problems with language and communication as the most important concerns, followed by developing social support networks and handling cultural differences (see Table 2).

Table 2. Key informant's rankings of international student concerns.

\begin{tabular}{ll}
\hline Concern & $\begin{array}{l}\text { Average Ranking } \\
(1-5, \text { with 1 being most important })\end{array}$ \\
\hline Communication problems & 1.4 \\
Create and maintain supportive relationships & 2.6 \\
Deal with cultural differences & 2.8 \\
Handle stress and emotions & 3.0 \\
Issues related to identity, identity/values confusion & 3.8 \\
& 4.0 \\
Family problems or conflict (at home or here) & 5.2 \\
Handle discrimination or racism & \\
\hline
\end{tabular}


Key informants stressed the importance of naming programs so as not to stigmatize or associate specifically with the mental health realm. One helpful suggestion was to invite groups of individuals and to use international student peers to advertise the programs. Some expressed the need for education, while another said, "education is good, but the problem is in their experience." Two informants stated that having a designated counselor for international students was a good idea, while two others mentioned that all counselors should be familiar with international student adjustment processes and concerns. Two key informants and several of the international student leaders suggested using international students as role models to help with adjustment.

\section{DISCUSSION}

According to the ASSIS and interviews, international students are experiencing distress across a range of areas. During interviews, it was challenging to distinguish concerns. For example, when communication problems exist they were inextricably linked to social difficulties and compromised academic performance. Members of the team agreed that students' primary concerns varied depending on individual, cultural, and language differences, as well as situational factors and levels of acculturation. Although scores on the ASSIS were not significantly correlated to length of stay, participants who had been in the US longer reported to have gone through more difficulties early on, but that over time they had worked out many problems. Reflecting on their experiences since arrival, students reported different types of difficulty at different times. For example, communication and practical living challenges were often more salient immediately after arrival, followed by academic challenges, realization of cultural differences, and finally, boredom or a lack of recreational outlets and social supports.

When asked for their input on programming, key informants and student leaders suggested paying attention to process aspects of marketing, recruiting, and facilitating programs. Group formats that allow for social interaction with other intentional students and with US students were among the most frequent suggestions. Creating a warm and inviting atmosphere, offering food, and facilitation of cultural sharing were encouraged.

\section{Reflection and Planning Phase}

The team reflected on the study results and developed an action plan for programming that included: 1) Establish a mentoring program by matching new international students with senior international students for advice and support, 2) Provide range of support services that socialize students to US academic and cultural systems, 3) Provide resource linkage and information about practical needs and adjustment early and continuously via programs, media, peers, 4) Offer education, discussions and group-based activities about a range of adjustment topics, 5) Encourage US student involvement with international students through range of casual, recreation activities, and 6) Enhance counselors and therapists awareness of and knowledge in working with international students.

Practical suggestions, which arose from the initial needs assessment were summarized and organized into a framework for program development. This is consistent with approaches described in the literature and used at other universities (Engel et al., 2007; Johnson \& Sandhu, 2007; Eldaba, 2016), yet the participatory approach used was incredibly informative in helping address unique concerns, and also respond to particular contextual challenges. Highlighting international student perspectives also provided an overall orientation that emphasizes serving 
and learning from international students, using their words, voices and ideas as guides in program planning and delivery.

\section{Program Development and Implementation Phase}

With the help of the needs assessment, two programs were piloted, a women's support group and a conversation group for practicing English and talking about adjustment concerns. Adjustments were made such as re-framing the groups away from a problem-focus. The reach of the groups was expanded through advertisements, networking, and the presence of facilitators at orientation. Another change was the co-facilitation of groups by graduate students in the psychology and counselor education programs, and joint supervision between departments. It allowed a more complete range of topic coverage, group processes and skills training (e.g., assertiveness training). In addition, an international student mentoring program was developed, a workshop series and an international cooking club (see table 3 ). One thing remains and that is the specific needs and desires tend to morph and change over time based on social and contextual features (changes in government, new public transport options), and also the desires of the members.

Table 3. Programs for international students.

Program Description

The International Ladies Club

Weekly meetings; Social and emotional support for international women; Activities include cooking and sharing food, visiting local cultural attractions, and celebrating cultural holidays

The Cultural Connections Club (“C3”) Mixed gender, open group; Adjustment concerns of international students; Safe and supportive environment

International Student Mentoring Program Two mentors (established international students) are assigned to work with 10 new international students; Mentors help with daily living challenges, and initial social and cultural adjustment

The Workshop Series

Evening workshops throughout the year on particular topics (e.g. "How to succeed in the American classroom")

The Cook, Eat, and Share Group

Closed group including American and international students; Participants explore culture and traditions through cooking and food

\section{Formative Feedback}

After programs were underway, a new phase of observation began whereby group facilitators reflected on successes (what seems to be working) and challenges (what is not working or needs to be addressed). Successes of the Cultural Connections Programs (CCP) included 1) development and offering of new programs, covering varied topics and meeting diverse needs, 2) new collaborations in group facilitation and supervision between counseling 
and psychology departments, and 3) enhanced communication and organization between stakeholders with increased program visibility. Successful cross-discipline collaboration (i.e. psychology and counseling students co-facilitating groups and providing supervision) brought new perspectives and exposure to new skills. The programs also provided highly valued opportunities for graduate students to build skills in multicultural counseling and intercultural communication (Jacob, 2001; Johnson, Bastien \& Hirschel, 2008).

The content of the programs and the facilitators were well received by attending students and many expressed that the discussions were helpful and that the activities were fun. While the facilitators discussed social, emotional, and relational concerns, the counselors approached psychological issues with sensitivity. Graduate students working with these groups reported a new level of awareness about indirect communication styles, the stigma associated with psychological distress, and the pervasiveness of stereotypes and biases. They had to adjust themselves to new ways of communication, and they had to learn creative ways to serve international students. For example, counselors reported that sharing food and other external cultural attributes often provided opportunities to discuss deeper cultural differences in a nonthreatening manner. Graduate facilitators continued making adjustments in their running of the group each semester following this study, such as increased social and recreational events, Outgrowths of the CCP were considered signs of success that an increasing network of support is being established.

Fluctuating attendance was one of the biggest challenges, which then often lacks the critical mass needed for success. Ongoing efforts had to be made to increase the visibility of programs. One of the main lessons learned from program implementation was the importance of outreach to build trust and relationships within the international community. As one facilitator stated, "As much time as you spend in the group, you need to spend outside the group."

A future step will be to elicit more formal feedback from stakeholders about programs, and also to measure the effectiveness of programs in reducing acculturative stress. Another step constitutes experimenting with classroom interventions to increase student awareness and intercultural interactions (Johnson, Bastien, \& Hirschel, 2009; Mio, Barker-Hackett, \& Tumambig, 2006). For example, in a multicultural psychology course, students interview an international student about their cultural background, perceptions of the United States, and their adjustment experiences. Although the assignment is often approached with apprehension and anxiety, students report it contributes to increased cultural awareness. Ongoing and sustained efforts to promote interest in international students, enhance social integration and reduce ethnocentrism are needed.

\section{Limitations}

One major limitation of this study is the lack of formal evaluations of the effectiveness of the programs that were implemented. However, qualitative data in the form of feedback from the international students who participated in the programs was collected throughout, and it was used in an ongoing process to improve the programs.

Another limitation was selection. Although our non-response rate was low, participants who chose to respond to our recruitment may have different views. However, the leaders and others spoke on behalf of those students during the group discussions. Students who are less outgoing and who are potentially struggling the most might not be represented in the data. It is unknown how this might influence the findings, yet our programs were designed to reduce stigma and maximize outreach. 
Finally, data was collected at a single university in the Southern US. Programs were designed to fit the needs of the participants of this study, and the particular context. At this point in time, no statements can be made about the generalizability of the proposed programs across other universities in the US. However, using a participatory research approach to help design and implement culturally and contextually appropriate programs appears to be a beneficial process and aligned with researcher and practitioner calls for a continual and multidimensional approach to meeting the mental health needs of international students (e.g. Arthur, 2008; Johnson \& Sandhu, 2007; Hwang, Bennett, \& Beauchemin, 2014).

\section{CONCLUSION}

In this participatory approach to program development, international students voiced concerns and provided a range of suggestions for promoting positive adjustment. While formal evaluations of programs are needed, we suggest that a participatory approach offers a promising avenue to culturally and contextually competent programming and delivery. In this study, concerns and suggestions, such as a need for more recreation opportunities, organized social events, and fostering relations and support with US students, were contextually situated, reflecting the semi-rural, Southern environment. Participatory research allows for reciprocal learning, such as enriched opportunities for graduate students to gain experiences and skills with diverse cultural groups. Finally, using ideas from stakeholders as a basis for inquiry, learning and program development, we can enhance the acceptability, relevance, and value of cultural adjustment programs.

\section{REFERENCES}

Arthur, N. (2008). Counseling international students. In P.B. Pedersen, J.G. Draguns, W.J.Lonner, \& J.E. Trimble (Eds.), Counseling across cultures (6 ${ }^{\text {th }}$ ed., pp. 275-290). Thousand Oaks, CA: Sage.

Bai, J. (2016). Perceived support as a predictor of acculturative stress among international students in the United States. Journal of International Students, 6(1), 93.

Constantine, M. G., Okazaki, S., \& Utsey, S. O. (2004). Self-concealment, social self-efficacy, acculturative stress, and depression in African, Asian, and Latin American international college students. American Journal of Orthopsychiatry, 74(3), 230.

Eldaba, A. (2016). An innovative model to design an academic and social development program for international college students. College Student Journal, 50(2), 171-178.

Engel, M. B., Insalaco, G., Singaravelu, H. D., \& Kennon, K. (2007). Programs and outreach for international students. In H. D. Singaravelu \& M. Pope (Eds.), A handbook for counseling international students in the United States (pp. 311-316). Alexandria, VA: American Counseling Association.

Gebhard, J. G. (2012). International students' adjustment problems and behaviors. Journal of International Students, 2(2), 184-193.

Hayes, R. L, \& Lin, H. R. (1994) Coming to America: Developing social support system for international students. Journal of Multicultural Counseling and Development, 22, 7-16.

Hirai, R., Frazier, P., \& Syed, M. (2015). Psychological and sociocultural adjustment of first-year international students: Trajectories and predictors. Journal of Counseling Psychology, 62(3), 438.

Hwang, B., Bennett, R., \& Beauchemin, J. (2014). International students' utilization of counseling services. College Student Journal, 48(3), 347-354.

Jackson, M., Ray, S., \& Bybell, D. (2013). International students in the US: Social and psychological adjustment. Journal of International Students, 3(1), 17-28. 
Jacob, E. J. (2001) Using counselor training and collaborative programming strategies in working with international students. Journal of Multicultural Counseling \& Development, 29, 73-89.

Johnson, L.R., Bastien, G., \& Hirschel., M. (2009). Psychotherapy in a culturally diverse World. In Eshun, S. \& Gurung. R. (Eds.), Culture and Mental Health: Sociocultural Influences, Theory, and Practice (pp. 115-148). West Sussex, UK: Wiley-Blackwell.

Johnson, L. R. \& Sandhu, D. S. (2007). Acculturation, Isolation and Adjustment Issues: Intervention strategies for counselors. In H. Singaravelu, \& M. Pope (Ed.), Handbook for counseling international students in the United States, (pp 13-35). VA: American Counseling Association.

Kemmis, S., McTaggart, R., \& Nixon, R. (2013). The action research planner: Doing critical participatory action research. Singapore: Springer Science \& Business Media.

Komiya, N, \& Eells, G, T. (2001). Predictors of attitudes toward seeking counseling among international students. Journal of College Counseling, 2, 153-161.

Lee, J. Y. (2014). Asian international students' barriers to joining group counseling. International journal of group psychotherapy, 64(4), 444-464.

Lee, E. J., Ditchman, N., Fong, M. W., Piper, L., \& Feigon, M. (2014). Mental health service seeking among Korean international students in the United States: A path analysis. Journal of Community Psychology, 42(6), 639-655.

Lewin, K. (1946). Action research and minority problems. Journal of Social Issues, 2, 34-46.

Miles, M. B., \& Huberman, A. M. (1994). Qualitative data analysis: An expanded sourcebook. Thousand Oaks, CA: Sage.

Mio, J.S., Barker-Hackett, L., \& Tumambig, (2006). Multicultural Psychology: Understanding our diverse communities. San Francisco, CA: McGraw-Hill.

Mori, S. (2000). Addressing the mental health concerns of international students. Journal of Counseling and Development, 78, 137-145.

Reason, P. \& Bradbury, H. (2001). Handbook of action research. Participative inquiry and practice. London: Sage.

Sandhu, D.S. (1994) An examination of the psychological needs of the international students: implications for counseling and psychotherapy. International Journal for the Advancement of Counseling, 17, 229-239.

Sandhu, D, S., \& Asrabadi, B, R. (1994) Development of an acculturative stress scale for international students: Preliminary findings. Psychological Reports, 75, 435-448.

Smiljanic, I. (2017). The role of attachment, travel experiences and English proficiency ininternational students' acculturative stress and depressive symptoms. Journal of International Students, 7(2), 188.

Smith, R. A., \& Khawaja, N. G. (2011). A review of the acculturation experiences of international students. International Journal of Intercultural Relations, 35(6), 699-713.

Tsai, W., Wang, K. T., \& Wei, M. (2017). Reciprocal relations between social self-efficacy and loneliness among Chinese international students. Asian American Journal of Psychology, 8(2), 94.

Walker, L.A. \& Conyne, R.K. (2007). Group work with international students. In H. Singaravelu and M. Pope (Eds.), Handbook for counseling international students in the United States (pp. 13-35). Alexandria, VA: American Counseling Association.

Williams, C. T., \& Johnson, L. R. (2011). Why can't we be friends? Multicultural attitudes and friendships with international students. International Journal of Intercultural Relations, 35(1), 41-48,

Yeh, C. J., \& Inose, M. (2003) International students reported English fluency, social support satisfaction, and social connectedness as predictors of acculturative stress. Counseling Psychology Quarterly, 16, 1,15-28.

LAURA R. JOHNSON, PhD, is an associate professor of psychology at the University of Mississippi where she teaches multicultural psychology and supervises outreach programming for international and 
study abroad students. Dr. Johnson's research includes positive youth development, intercultural attitudes, conservation behaviors, and civic engagement, with a focus on East African youth and the internationalization of psychology. Email: ljohnson@olemiss.edu

TANJA SEIFEN-ADKINS, M.S., is a graduate student in the clinical psychology doctoral program at the University of Mississippi. She received her M.S. in Psychology from the University of Bonn in Germany. Tanja has co-facilitated several outreach programs for international at the University of Mississippi. Her research interests include adjustment and psychological well-being of international students, intercultural competence, and sexual competence among young adults. Email: tseifen@go.olemiss.edu

DAYA SINGH SANDHU, EdD, is a professor of counselor education and supervision and Director of Research at the Lindsey Wilson College in Columbia, Kentucky. Dr. Sandhu is a three-time recipient of the Senior Fulbright Research Fellowship for India. Dr. Sandhu's research interests include multicultural and diversity issues, with a special focus on the South Asian Americans and internationalization of professional counseling, and the role of spirituality in counseling and psychotherapy. Email: Sandhud@lindsey.edu.

NADEZDA "NADIA" ARBLES, PhD, co-founded and co-facilitated The Cultural Connections Program at The University of Mississippi during six years of her graduate studies. Her research primarily was focused on the experiences of international students in the process of adjustment and acculturation. Her other research interests included narrative approaches and metaphors in counseling. She is currently specializing in adventure therapy within Healing Hikes Hawai'i private practice. Email: nadiarbles@yahoo.com

HITOMI MAKINO, PhD, LPC, is an outpatient therapist at Inova Kellar Center, where she works with children, adolescents, and adults from diverse cultural backgrounds in Northern Virginia for various emotional, relational and family problems. She received her M.Ed. in Community Counseling from the University of Mississippi and her doctorate degree in Professional Counseling from Liberty University. Her research interests include Emotional Intelligence, attachment theory, integration of Christian faith in counseling, and cross-cultural counseling. Email: makinohitomi1@gmail.com 